\title{
A PERSPECTIVA DE DOCENTES DE UMA UNIVERSIDADE FEDERAL SOBRE A IMPLANTAÇÃO DO BIM NA GRADUAÇÃO EM ENGENHARIA CIVIL
}

Gabriela Rodrigues da Costa - gabrielarcosta20@gmail.com Antonio Jean Nascimento de Castro - antoniojean1@hotmail.com Luís Felipe Cândido - luisfcandido2015@hotmail.com

Núcleo de Inovação da Construção, Universidade Federal do Ceará, Campus de Crateús BR 226, Km 4, Venâncios 63750-000 - Crateús - Ceará

Resumo: O objetivo deste artigo foi analisar a percepção de docentes quanto à utilização do BIM na graduação em engenharia civil em uma universidade federal no interior do nordeste brasileiro. Para tal, foi realizada uma entrevista em profundidade com todos os docentes que lecionam as disciplinas profissionalizantes do curso de engenharia civil, totalizando oito entrevistados, buscando compreender a relação que estes possuem com o BIM e como veem a aplicação desta metodologia no curso. Verificou-se que o contato dos professores com BIM é superficial, representando uma barreira para a inserção no curso. Apenas três docentes manifestaram desejo de implementar BIM em suas disciplinas e apenas um já abordava o assunto, mesmo que de maneira superficial. Verificou-se a concordarem com a implementação, embora não tenham sido observadas estratégias para sua consecução, bem como a principal motivação citada foi o alinhamento com o mercado, com poucas citações ao ensino.

Palavras-chave: BIM. BIM no ensino. Ensino de Engenharia.

\section{INTRODUÇÃO}

A inserção BIM (do inglês Building Information Modeling, traduzido como Modelagem de Informação da Construção) na Indústria da Construção Civil tem estimulado uma grande reorganização setorial (AMORIM; KASSEM, 2015), tornando o processo de projeto nesta área mais colaborativo e integrado (GARBINI; BRANDÃO, 2014), o que exige uma readequação de perfil, tanto dos profissionais já atuantes como dos futuros (KEHL et al., 2018).

Entretanto, são poucos os profissionais que possuem amplo domínio sobre o BIM e tem capacidade de trabalhar de forma colaborativa neste novo paradigma (BARISON; SANTOS, 2011), o que pode contribuir para a incipiente adoção BIM pelo setor brasileiro como aponta relatório da McGraw-Hill (2014). Neste contexto, as instituições de ensino possuem um importante papel (RUSCHEL; ANDRADE; MORAIS, 2013), pois contribuem para a difusão da temática BIM e são capazes de readequar habilidades e competências dos futuros profissionais, qualificando-os para atender e impulsionar as demandas de mercado.

Contudo, Ruschel, Andrade e Morais (2013) mostraram que a adoção BIM no ensino ocorre de modo pouco efetivo. Já Kehl et al. (2018) evidenciaram a baixa familiarização de estudantes com o BIM no âmbito acadêmico de um curso de Arquitetura e Urbanismo. Percebese assim a lenta mudança existente, o que levou a investigação sobre a implantação BIM no ensino. 
Como agentes ativos no ensino-aprendizagem, os professores necessitam de uma boa compreensão sobre conceitos BIM, sendo este um dos pontos cruciais para a implementação desta metodologia ao ensino (RUSCHEL; ANDRADE; MORAIS, 2013). Barison e Santos (2015) corroboram que o primeiro passo para a introdução BIM ao currículo é compreender a visão dos docentes sobre a temática. Assim, a questão motivadora de pesquisa foi: qual a percepção de docentes sobre o uso do BIM na graduação em engenharia civil?

Assim, este trabalho teve como objetivo analisar a percepção dos docentes quanto ao uso do BIM na graduação em engenharia civil em uma universidade federal no interior do nordeste brasileiro. Desta forma, pode-se contribuir para que estratégias para a iminente inserção BIM possam ser traçadas no campus da universidade em estudo, bem como em outras realidades. Contribui-se, também, com a melhor compreensão de um fenômeno em emergência, cuja sedimentação depende de esforços contínuos tanto da indústria como da academia.

\section{BIM NO ENSINO DE ENGENHARIA}

O BIM é conceituado por Succar (2009) como um conjunto de tecnologias, políticas e processos que interagem entre si e se sobrepõem para formar uma metodologia de gerenciamento de informações atuante em todo o ciclo de vida de um empreendimento, por meio de um modelo digital. Succar e Kassem (2015) complementam que o BIM é o principal vetor de inovação na indústria da construção civil, pois ele pode modificar as entregas, relacionamentos e funções do setor.

De acordo com o Manual BIM Planning Guide For Facility Owners da Penn State University (CIC, 2013) o modelo digital gerado na metodologia melhora a visualização de elementos construtivos, facilita a extração de quantitativos e otimiza a elaboração de orçamentos, contribuindo com a engenharia de custos, as análises de engenharia e de conflitos.

A reestruturação do ciclo de vida de um empreendimento gerada pelo BIM torna necessário a formação de profissionais que saibam trabalhar de forma colaborativa (BARISON; SANTOS, 2011). Contudo, a ausência destes profissionais é uma das principais barreiras que impede a adoção BIM no mercado (KEHL et al., 2018).

Segundo Barison e Santos (2010), a implantação BIM no ensino deve ocorrer de acordo com estratégias de ensino-aprendizagem vinculadas aos níveis de competência BIM: introdutório, com a formação de modeladores BIM; intermediário, onde são formados analistas BIM; e avançado, com o surgimento dos gerentes BIM. Cada nível fornece aos alunos maior capacidade de trabalhar com o BIM quando forem inseridos no mercado de trabalho.

Desta forma foram desenvolvidos diversos estudos (KEHL et al., 2018; CRUZ; CUPERSCHMID; RUSCHEL, 2017; RUSCHEL; ANDRADE; MORAIS, 2013) que identificaram as principais barreiras e facilitadores para a implantação BIM. Contudo, é necessário analisar com maior profundidade a perspectiva dos docentes acerca desta implantação, tendo em vista que eles são agentes primários na formação dos novos profissionais e, em sua maioria, não foram introduzidos ao BIM em sua formação.

\section{METODOLOGIA}

A presente pesquisa foi realizada por meio de oito entrevistas em profundidade (RICHARDSON, 2011) cujo roteiro foi composto por 16 questionamentos, sendo três questões objetivas - enunciadas para serem analisadas: (i) questão 9 - quais softwares BIM você conhece/teve contato e em que nível os opera; (ii) questão 15 - as barreiras e dificuldades para 
introdução BIM em nosso curso; e (iii) questão 16 - contribuições BIM para o aprendizado dos alunos.

Realizou-se análise de conteúdo seguindo as etapas de Bardin (2011): (i) pré-análise; (ii) exploração do material e o tratamento dos resultados; e (iii) inferência e interpretação. $\mathrm{O}$ Quadro 1 apresenta uma breve caracterização dos participantes da pesquisa.

Quadro 1 - Caracterização dos docentes

\begin{tabular}{|c|c|c|c|c|c|}
\hline \multicolumn{2}{|c|}{ Características } & Docentes & \multicolumn{2}{|c|}{ Características } & Docentes \\
\hline \multirow{2}{*}{ Gênero } & Feminino & 3 & \multirow{2}{*}{ Nível de formação } & Mestrado & 7 \\
\hline & Masculino & 5 & & Doutorado & 1 \\
\hline \multirow{3}{*}{$\begin{array}{c}\text { Experiência } \\
\text { docente (anos) }\end{array}$} & $<1$ & 1 & \multirow{6}{*}{ Área de atuação } & $\begin{array}{c}\text { Construção } \\
\text { Civil }\end{array}$ & 3 \\
\hline & De 1 a 5 & 6 & & Estruturas & 2 \\
\hline & $>5$ & 1 & & Geotecnia & 1 \\
\hline \multirow{3}{*}{$\begin{array}{c}\text { Experiência } \\
\text { profissional (anos) }\end{array}$} & $<1$ & 1 & & $\begin{array}{l}\text { Recursos } \\
\text { Hídricos }\end{array}$ & 1 \\
\hline & De 1 a 5 & 6 & & Saneamento & 2 \\
\hline & $>5$ & 1 & & Transportes & 1 \\
\hline
\end{tabular}

Fonte: dos autores

Ressalta-se que foram entrevistados todos os docentes do ciclo profissionalizante em exercício em 2019, ou seja, os de formação em engenharia que lecionam as principais disciplinas formativas do curso. Quanto ao perfil dos respondentes, seis deles possuem entre 1 e 5 anos de experiência docente, o que indica que o corpo docente é relativamente jovem para o padrão de Universidades Públicas, como observado por Pereira e Ribeiro (2014). Contudo, deve-se levar em consideração que o campus é novo, tendo formado a sua primeira turma de engenharia civil em 2019. Apenas um dos professores tem doutorado, sendo todos de formação básica em engenharia civil. Quanto a área de atuação o número de menções é superior ao número de respondentes, pois alguns professores atuam em mais de uma área de acordo com os próprios entrevistados. Os docentes foram nomeados de " $\mathrm{A}$ " a " $\mathrm{H}$ " para assegurar o sigilo das suas identidades.

\section{RESULTADOS E DISCUSSÕES}

\subsection{Envolvimento com BIM}

Sete dos oito entrevistados afirmaram conhecer o BIM e apontaram os meios diferentes pelos quais tiveram contato com a metodologia, conforme apresentado na Figura 1.

O mercado de trabalho foi a principal forma de contato mencionada pelos professores. Ao cruzar este dado com a variável tempo é possível inferir que a metodologia BIM está presente há mais tempo no mercado de trabalho, mesmo que de forma introdutória, pois cinco dos entrevistados conhecem BIM a mais de três anos. Por outro lado, apenas um dos entrevistados informou que teve contato com BIM em sua graduação. Isto indica a baixa presença da temática no ensino de graduação e dificulta a adoção da temática, tendo em vista que, como os docentes não estudaram BIM em profundidade durante sua graduação, é natural que estes tenham maior dificuldade em incorporar esta metodologia nas disciplinas que lecionam. 
Figura 1 - Formas de contato com BIM

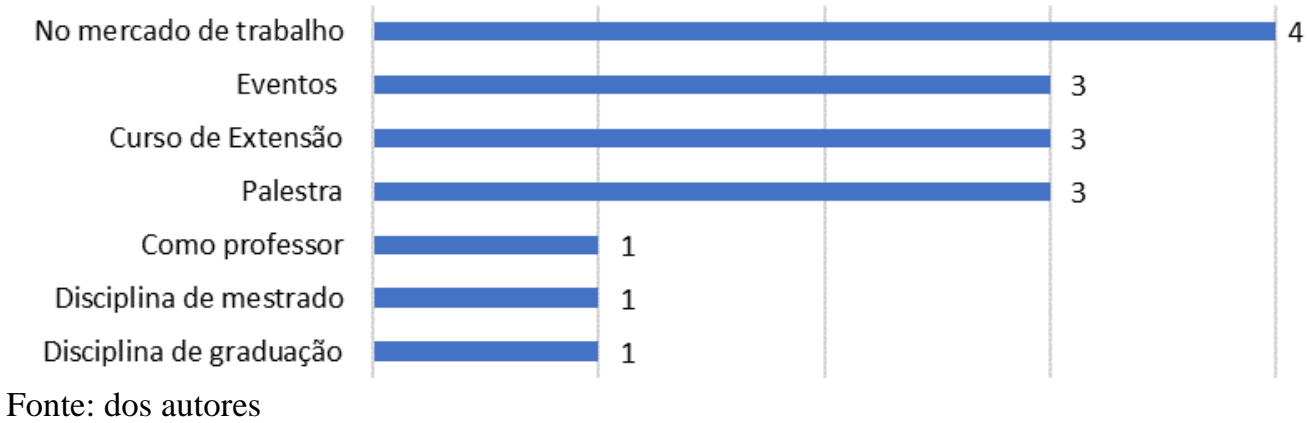

Quanto ao nível de conhecimento autoatribuído pelos professores em relação ao BIM, verificou-se que apenas um dos docentes se autoavaliou com nível de conhecimento intermediário, enquanto quatro se consideram iniciantes e três acreditam que o conhecimento que possuem é tão superficial que não se encaixa em nenhum nível. Esse fato expõe a falta de conhecimento do corpo docente, o que pode dificultar uma correta adoção BIM nas universidades.

Entre os entrevistados que já tiveram contato com BIM, apenas três se envolveram em alguma atividade relacionada à temática após o primeiro contato. Fazer cursos e realizar pesquisas científicas foram citados duas vezes cada, estudar por conta própria e fazer MBA tiveram uma menção cada. Percebe-se a baixa variedade de atividades, o que somado ao fato de que apenas dois docentes se envolveram em duas ou mais atividades distintas, indica o baixo envolvimento dos entrevistados com BIM.

Com relação ao nível de operação de softwares BIM, apenas um docente utiliza um software (Tekla BIMsight) de forma plena. Essa realidade é preocupante pois a familiaridade com estes softwares pode auxiliar de forma mais ativa a aprendizagem dos alunos. Destaca-se ainda que apenas dois professores possuem formações específicas em softwares BIM. Contudo, eles não aplicam BIM em suas disciplinas e tampouco possuem envolvimento com esta temática no campus.

Questionados sobre o desejo de aperfeiçoar os conhecimentos em BIM, apenas o docente F não mostrou interesse, afirmando que "Hoje, diante das áreas que eu trabalho, que eu pesquiso, eu não vejo aplicabilidade [...], então ainda não”. Outros dois consideram estudar se conhecerem aplicações em suas disciplinas, enquanto cinco demostraram interesse em se aprofundar e os meios para isso são apresentados na Tabela 1.

Tabela 1 - Meios para aprimorar o conhecimento sobre o tema

\begin{tabular}{ccc}
\hline Meio & Quantidade & Relativa \\
\hline Estudar por conta própria & 6 & $33 \%$ \\
\hline Fazer um curso & 4 & $22 \%$ \\
\hline Participar de um grupo de estudos & 3 & $17 \%$ \\
\hline Participar de um evento sobre o tema & 2 & $11 \%$ \\
\hline Fazer uma pesquisa científica & 2 & $11 \%$ \\
\hline Projeto fora do âmbito acadêmico & 1 & $6 \%$ \\
\hline Total de menções & 18 & $100 \%$ \\
\hline
\end{tabular}

Fonte: dos autores

O total de menções é de 18, indicando que os professores consideram mais de uma opção para continuarem/iniciarem a estudar sobre a temática BIM. Isso mostra que os docentes estão 
propensos a se aperfeiçoarem na temática e que a resistência à novas tecnologias e a estabilidade profissional podem não se caracterizar como impedimentos determinantes à inserção BIM no campus, corroborando com Böes (2019).

\subsection{A perspectiva de implantação do BIM no curso}

Quando questionados se o curso possui alguma disciplina que esteja aplicando BIM três dos oito respondentes afirmaram não saber. Além disso, 4 afirmam que há disciplinas que abordam BIM, mas apenas o docente $\mathrm{C}$ afirmou aplicar BIM na disciplina que leciona, ainda que "[...] não de maneira direta, ensinando, mas incentivando ao uso e tento falar na disciplina". Isso comprova a incipiência, o que dificulta a prática de um ensino integrado e colaborativo, tanto na temática BIM quanto na formação em geral.

Por outro lado, há uma alta concordância dos entrevistados em relação às disciplinas que possuem possíveis aplicabilidades BIM, como apresentado na Figura 2.

Figura 2 - Reconhecimento de disciplinas com aplicabilidade BIM

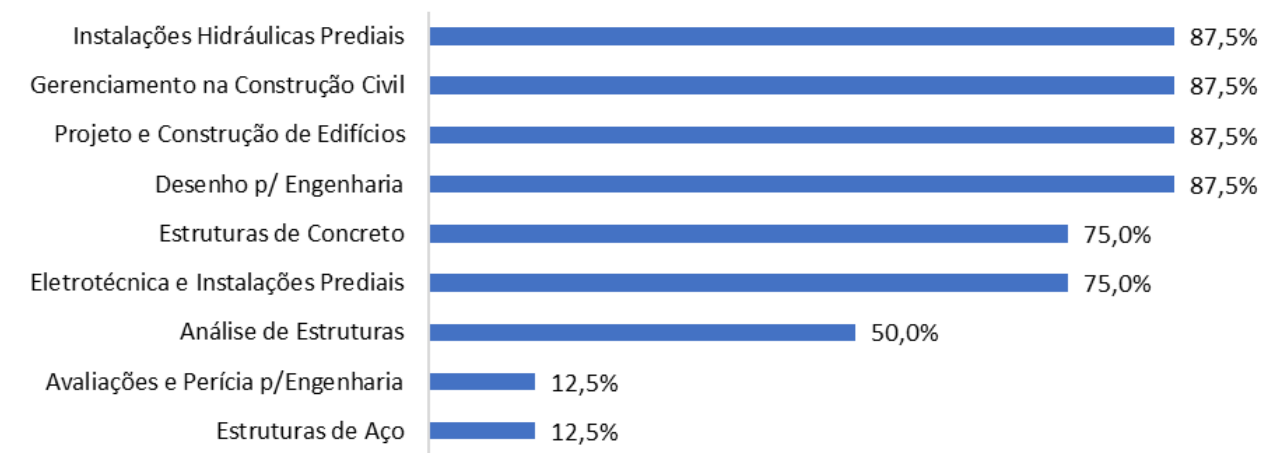

Fonte: dos autores.

Percebe-se que todas as disciplinas citadas se relacionam com a área da construção civil e possuem como foco de estudo o edifício. Isso comprova que os professores conhecem, mesmo que superficialmente, os conceitos básicos do BIM, pois as aplicações mais disseminadas desta metodologia apontadas pela literatura são direcionadas às etapas do ciclo de vida de uma edificação. Além disso, a quantidade de disciplinas com aplicabilidade BIM apontadas por mais de $50 \%$ dos docentes ressalta a importância de incorporar a temática nestas disciplinas.

A Figura 3 apresenta a concordância dos professores com as contribuições do BIM ao aprendizado dos alunos.

Figura 3 - Contribuições do BIM para o aprendizado

Melhora a qualidade dos projetos

Ajuda na visualização e compreensão dos conceitos

Auxilia na aplicação dos conceitos aprendidos

Aumenta a interdisciplinaridade

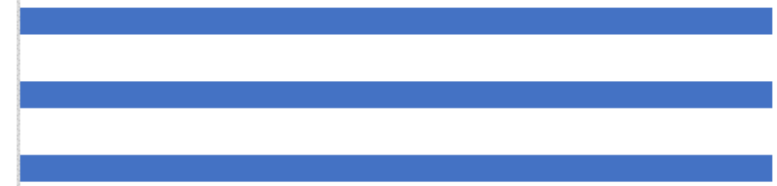

Fonte: dos autores

Percebe-se a alta concordância com a maioria das contribuições indicadas, o que demonstra que os docentes reconhecem a importância do BIM no ensino, mesmo que não o implementem. 
Contudo, a concordância foi baixa para a otimização do tempo na realização de trabalhos, pois os professores acreditam que, caso o aluno ainda não domine os softwares BIM, o tempo gasto será maior do que o habitual. Esta opinião fica explícita nas falas dos docentes $\mathrm{C}$ e $\mathrm{F}$, respectivamente: "Eu não acho que [...] ajuda a reduzir porque se eles tiverem aprendendo para poder aplicar vai é aumentar o ciclo"; "Ajuda a reduzir o tempo... depende. Se o aluno souber mexer, se não souber não ajuda".

Ao serem indagados se concordam com a inserção BIM na estrutura curricular do curso, sete dos oito professores responderam positivamente. $O$ docente $G$, que respondeu de forma negativa, citou que: “[...] deve ser abordado nas disciplinas. [...] É uma metodologia né (sic.), mas acho que a cadeira de Gerenciamento... deve ser abordado dentro dela [...]”. Esta percepção contrasta com a do docente $\mathrm{C}$ que acredita na interdisciplinaridade: "[...] ela [metodologia BIM] deve ser incorporada integralmente na disciplina [...] então você entende que em um pensamento BIM você constrói uma metodologia de projeto e construção virtual para agregar mais conhecimento aos discentes. E aí isso vai favorecer a interdisciplinaridade [...]".

É possível perceber também as diferentes visões que os docentes possuem sobre BIM. Para os professores $\mathrm{C}$ e $\mathrm{G}, \mathrm{BIM}$ é uma metodologia, já para o docente $\mathrm{B}$, uma ferramenta, como evidenciado em sua fala: "[...] é uma ferramenta de projeto/planejamento/ análise e gestão magnífica que já está sendo implementada inclusive no mercado brasileiro. A falta desta disciplina pode representar uma grande desvantagem para os alunos". Essas diferentes perspectivas dos docentes podem influenciar as motivações para aplicar na graduação e a atual capacidade de agirem como difusores e moderadores de conhecimento.

Nas falas dos docentes A e F, respectivamente, é nítida a preocupação em formar profissionais alinhados com o mercado de trabalho e a possibilidade de diferencial: "Porque hoje é fundamental o uso dele nas diversas áreas da engenharia, a gente[curso] precisa ter esse conhecimento para que os alunos saiam de forma a aplicar diretamente no mercado, sendo que hoje o mercado já exige ou se não, na empresa especificamente ele ter isso como diferencial.”; "[...] pra quem sai da universidade hoje é importante já ter tido algum contato, e lá fora conseguir se desenvolver mais no mercado, porque hoje é um diferencial para as empresas alguém que trabalhe e conheça o BIM [...]”.

Das falas depreende-se os motivos para implantação BIM que foram divididos em 4 categorias, conforme exibido na Tabela 2.

Tabela 2 - Por quais motivos o BIM deve ser incorporado a estrutura curricular?

\begin{tabular}{ccc}
\hline Motivos & Quantidade & Relativa \\
\hline Alinhamento com o mercado & 5 & $62,5 \%$ \\
\hline Favorece a interdisciplinaridade & 1 & $12,5 \%$ \\
\hline Materializar e visualizar conceitos & 1 & $12,5 \%$ \\
\hline Inovação & 1 & $12,5 \%$ \\
\hline
\end{tabular}

Fonte: dos autores

Majoritariamente, eles acreditam que a incorporação BIM na estrutura curricular pode promover o alinhamento com o mercado. Por um lado, isso é positivo, pois evidencia que os docentes estão cientes em relação as demandas do mercado e reconhecem a necessidade de que os novos profissionais sejam capacitados com conhecimentos BIM. Em contrapartida isso também revela a baixa importância que os entrevistados dão aos benefícios que o BIM pode fornecer ao ensino, uma vez que apenas a materialização e visualização de conceitos e o favorecimento da interdisciplinaridade foram mencionados, e somente com uma menção cada. 
Apenas três dos oito entrevistados pretendem incluir BIM em suas disciplinas, o que é preocupante, sendo a proporção $(37,5 \%)$ inferior até mesmo à quantidade de docentes que já abordam BIM (54\%) relatada em outros estudos, como em Cruz, Cuperschmid e Ruschel (2017). Outros três docentes mostram-se indecisos sobre a inclusão BIM, devido à carga horária adicional e a falta de conhecimento sobre o tema.

Os docentes que desejam implantar o BIM em suas disciplinas indicaram cinco vertentes de aplicação: execução de projetos, modelagens, orçamentos, planejamentos e como recurso para auxiliar na visualização de conceitos. Estas implementações, se completamente realizadas, levariam o curso ao nível introdutório de BIM no ensino, segundo a classificação de Barison e Santos (2010), alcançado com a modelagem e a explanação de conceitos BIM.

Por fim, a Figura 4 exibe a concordância com as barreiras para implantação BIM no curso na percepção dos entrevistados.

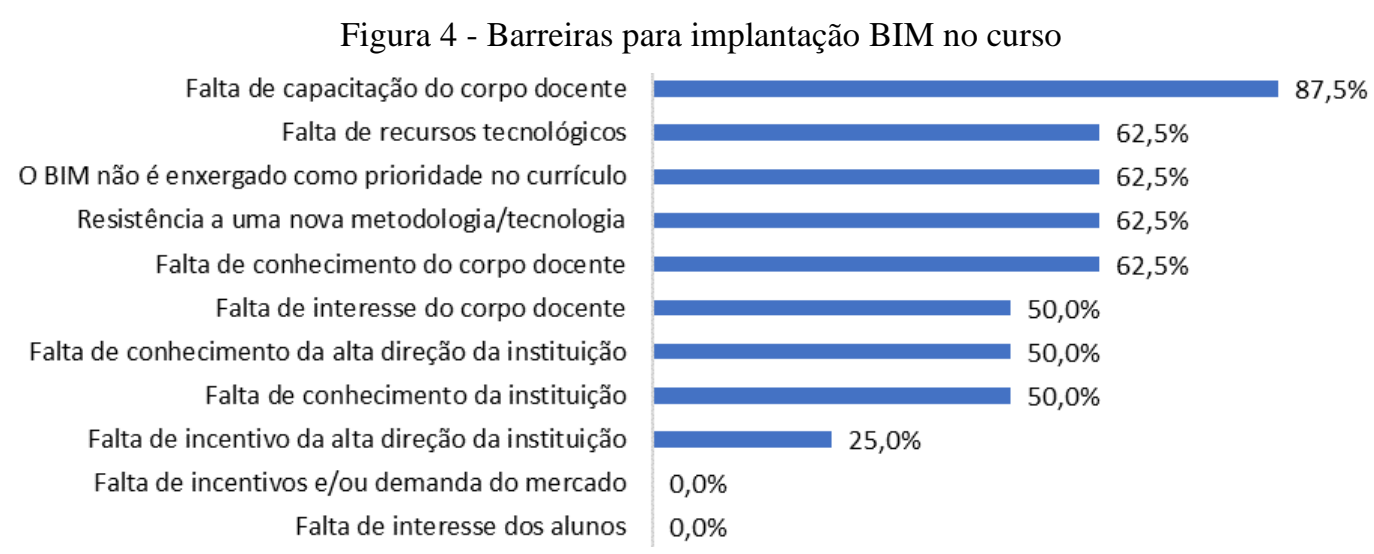

Fonte: dos autores

A falta de capacitação do corpo docente $(87,5 \%)$ foi a principal barreira, corroborando com os resultados obtidos nas análises anteriores que relatam a ausência de formações específicas em BIM. A falta de conhecimento do corpo docente $(62,5 \%)$, também ratifica os resultados, tendo em vista que 50\% dos professores se consideram iniciantes na temática e 37,5\% não se enxergam em nenhum nível. Verifica-se também a alta concordância com a falta de recursos tecnológicos $(62,5 \%)$, pois além dos softwares BIM há a necessidade de hardware mais potente. Outra barreira com elevada concordância foi a baixa prioridade dada ao BIM no currículo $(62,5 \%)$, que é evidenciada pela ausência de conteúdos na estrutura curricular do curso.

Destaca-se que os professores concordaram com a resistência a uma nova metodologia $(62,5 \%)$ e a falta de interesse do corpo docente $(50 \%)$. Aparentemente isso vai de encontro às análises já realizadas, pois apenas um professor não demonstrou interesse em aprender mais sobre BIM e somente outro acha que a metodologia não deve ser inserida na estrutura curricular. Porém, pode-se destacar que, nesta análise, os professores estão também avaliando uns aos outros, o que pode diferir da sua autoavaliação que indicou a propensão a se engajarem com a temática. Também é importante ressaltar que nenhum entrevistado indicou a falta de interesse dos alunos e de incentivo/ou demanda de mercado como empecilhos para implantação BIM.

\section{CONSIDERAÇÕES FINAIS}

Este trabalho teve como objetivo analisar a percepção dos docentes quanto ao uso BIM na graduação em engenharia civil. Para tal, realizou-se um estudo com oito docentes de uma universidade federal no interior do nordeste brasileiro, o que possibilitou a compreensão de 
diversos aspectos inerentes à temática que podem ajudar na implantação do BIM no próprio curso analisado, bem como em outras realidades.

Verificou-se que sete dos oito docentes já tiveram algum tipo de contato com a temática e que este ocorreu principalmente no mercado de trabalho (para quatro docentes), em detrimento das disciplinas de graduação (apenas um). Desta forma, constata-se que a indústria da construção civil já faz uso do BIM, ao contrário da graduação, que pouco influenciou no conhecimento dos docentes sobre a temática. Isto pode limitar a forma como as disciplinas são pensadas, pois naturalmente os professores têm como modelo preliminar as próprias disciplinas que cursaram na sua graduação, o que pode dificultar a adoção BIM. Esta constatação reforça a importância de estudos que apresentem modelos de disciplinas e experiências inovadores que possam ajudar na reconfiguração das disciplinas, constituindo prolífica agenda de pesquisa.

Também foi constatado que professores se consideram iniciantes na temática BIM, tendose uma grande lacuna formativa, pois apenas dois docentes possuem formações específicas em BIM e somente um utiliza plenamente um software BIM. Isso reforça o baixo conhecimento e a falta de capacitação do corpo docente indicados como empecilhos para adoção BIM. Essa é uma problemática mais estrutural, cuja solução depende de esforços contínuos dos próprios docentes e que podem ser estimulados institucionalmente, por meio de incentivos à capacitação, bem como a própria inclusão estratégica da temática no Projeto Pedagógico de Curso.

A inserção BIM na estrutura curricular tem sido tão baixa que três dos oito respondentes não sabiam se havia disciplinas que faziam uso da metodologia, enquanto quatro afirmam que o BIM era aplicado em alguma disciplina. Ou seja, poucos aplicavam e poucos sabiam que outros aplicavam. Apenas um professor aborda a temática e ainda de maneira indireta, o que demonstra o baixo diálogo entre os docentes sobre BIM que pode resultar em uma maior dificuldade para a prática de um ensino integrado e colaborativo.

Os professores reconheceram a aplicabilidade BIM nas disciplinas, principalmente naquelas cujo objeto de estudo é o edifício, e concordam que esta metodologia contribui para o aprendizado, através da melhora na qualidade dos projetos, aumento da interdisciplinaridade e auxílio na visualização, compreensão e aplicação de conceitos de engenharia.

Destaca-se que sete dos oito concordaram com a inserção BIM na estrutura curricular, mas apenas três pretendem incluir a metodologia nas próprias disciplinas. Isto ocorre, pois uma parte dos professores (três) têm dúvidas sobre a implantação, por não conhecer bem a temática e por receio de que a carga horária da disciplina seja um empecilho, enquanto outros dois não demonstraram interesse. Além disso, os motivos apontados para a incorporação BIM remetem principalmente ao alinhamento com o mercado, sendo baixa a importância vista sobre os benefícios que o BIM pode trazer para o ensino.

Desta forma, pode-se concluir que o contato dos professores com BIM ocorreu de maneira difusa e pontual e que o envolvimento deles ainda é superficial, o que representa uma barreira determinante para a implantação BIM na graduação. Além disso, a maioria dos professores têm pouco conhecimento sobre o que ocorre em disciplinas que não leciona, o que tem gerado atualmente perspectivas de iniciativas isoladas de aplicação BIM, sem que ocorra uma integração que alinhe os conteúdos abordados nas diversas disciplinas do curso.

Todavia, ressalta-se que embora os professores tenham indicado a resistência a novas metodologias/tecnologias como empecilho para adoção BIM, eles têm interesse em aprofundar os conhecimentos em BIM e somente um dos oito entrevistados discorda da implantação desta metodologia na estrutura curricular. Constatou-se a baixa prioridade dada ao BIM no currículo como uma das barreiras para adoção BIM, não sendo possível observar indícios de uma organização institucional para reverter este quadro. 
Desta forma, para trabalhos futuros, sugere-se a elaboração de estratégias efetivas para inserção BIM na graduação, de forma a contornar as barreiras identificadas neste trabalho.

\section{Agradecimentos}

À Pró-reitoria de Graduação (PROGRAD) da Universidade Federal do Ceará (UFC) pelo apoio e aos entrevistados pelo tempo concedido e informações prestadas.

\section{REFERÊNCIAS}

AMORIM, S.R.L; KASSEM. M. Building Information Modeling no Brasil e na União Européia. Brasília, 2015.

BARDIN, L. Análise de conteúdo. São Paulo: Edições 70, 2011. 279p.

BARISON, M. B.; SANTOS, E. T. BIM teaching strategies: an overview of the current approaches. In: INTERNATIONAL CONFERENCE ON COMPUTING IN CIVIL AND BUILDING ENGINEERING, 10., 2010, Nottingham. Proceedings...Nottingham: Nottingham University Press, 2010.

BARISON, M. B.; SANTOS, E. T. Ensino de BIM: Tendências atuais no cenário Internacional. Gestão \& Tecnologia de Projetos, São Carlos, v. 6, n. 2, p. 67-80, dez./2011.

BARISON, M. B.; SANTOS, E. T. Percepções de professores quanto à introdução de BIM no currículo. In: ENCONTRO BRASILEIRO DE TECNOLOGIA DE INFORMAÇÃO E COMUNICAÇÃO NA CONSTRUÇÃO, 7., 2015, Recife. Anais... Porto Alegre: ANTAC, 2015.

BÖES, J. S. Proposta de plano de implantação do BIM na indústria da construção civil. 2019. Dissertação (Mestrado em Engenharia Civil) - Programa de Pós-Graduação em Engenharia Civil: Estruturas e Construção Civil, Universidade Federal do Ceará, Fortaleza. 2019.

CIC. BIM: Planning guide for facility owners (version 2.0). Penn State University, 69p., 2013.

CRUZ, M. O.; CUPERSCHMID, A.; RUSCHEL, R. C. A incorporação de BIM no ensino do curso Técnico em edificações. Gestão \& Tecnologia de Projetos, São Carlos, v. 12, n. 2, p. 117-134. 2017.

GARBINI, M. A. L.; BRANDÃO, D. Q. Proposta de modelo para implantação de processo de projeto utilizando o conceito BIM em escritórios de arquitetura. Gestão e Tecnologia de Projetos, São Paulo, v. 9, n. 1, p. 7-24, jan./jun, 2014.

KEHL, C., STUMPF, C. D., ROSA, D. C., SILVA, A. F., ISATTO, L. E. Ensino de BIM em um curso de Arquitetura e Urbanismo: avaliação da percepção de demanda. In: ENCONTRO NACIONAL DE TECNOLOGIA DO AMBIENTE CONSTRUÍDO, 17., 2018, Foz do Iguaçu. Anais... Porto Alegre: ANTAC, 2018. 
MCGRAW HILL, C. The Business Value of BIM for Construction in Major Global Markets: how contractors around the world are driving innovation with the Building Information Modeling. SmartMarket Report, p. 60, 2014.

PEREIRA, P.; RIBEIRO, R. A Inserção do BIM no Curso de Graduação em Engenharia Civil. In: CONGRESSO BRASILEIRO DE EDUCAÇÃO EM ENGENHARIA, 42., Juiz de Fora, 2014. Anais... Juiz de Fora: Cobenge, 2014.

RICHARDSON, R. J. Pesquisa Social: métodos e técnicas. 3. ed. São Paulo: Atlas, 2011.

RUSCHEL, R. C., ANDRADE, M. L. V. X. de, MORAIS, M. de. O ensino de BIM no Brasil: onde estamos? Ambiente Construído, Porto Alegre, v. 13, n. 2, p. 151-165, 2013.

SUCCAR, B. Building information modelling framework: A research and delivery foundation for industry stakeholders. Automation in construction, v. 18, n. 3, p. 357-375, 2009.

SUCCAR, B; KASSEM, M. Macro-BIM adoption: Conceptual structures. Automation in Construction. 57, 64-79. 2015.

\title{
THE PERSPECTIVE OF PROFESSORS FROM A FEDERAL UNIVERSITY ON THE IMPLEMENTATION OF BIM IN THE GRADUATION IN CIVIL ENGINEERING
}

\begin{abstract}
This paper aimed to analyzes the perception of engineering professor regarding the use of BIM in undergraduate civil engineering at a federal university in the interior of brazilian northeast. For that, an in-depth interview was conducted with all professors who teach the professional disciplines of the civil engineering course, totaling eight respondents, seeking to understand the relationship they have with BIM and how they see the application of this methodology in the course. It was found that the professors involvement with BIM is superficial, representing a barrier to insertion in the course. Only three professors pointed the desire to implement BIM in their subjects and only one already addresses the subject, but in a superficial manner. Despite of the agreeing of respondents with the need for BIM implementation, no strategies for that were observed. In addition, the main motivation cited refers to market alignment, with few citations linking BIM with engineering teaching.
\end{abstract}

Keywords: BIM. BIM in Teaching. Teaching engineering. 